\title{
A Physische Geographie de Immanuel Kant: descrição, história da natureza
}

\author{
A Physische Geographie de Immanuel Kant: descripción, historia \\ de la naturaleza
}

\author{
Immanuel Kant's Physische Geographie: Description, History \\ of Nature
}

\author{
Antonio Carlos Vitte \\ acvitte@ige.unicamp.br \\ Universidade de Campinas
}

Resumo: O artigo procura relacionar a geografia e a filosofia kantianas. Para Kant a geografia seria a única ciência capaz de trabalhar o empírico e o transcendental, compondo uma relação multiescalar, de acordo com a qual a descrição geográfica, associada à noção de história da natureza poderia reconstruir os processos e as paisagens do passado e fornecer explicações para as paisagens atuais. Outro fato importante é que a reflexão geográfica de Kant estava fortemente embebida de uma dura geografia política, que justificava epistemologicamente a ocupação de todos os espaços da superfície da Terra pelo modo de produção capitalista, segregando os continentes e seus povos.

Palavras-chave: Kant. Geografia Física. Descrição da natureza. História da natureza. Cosmopolitismo.

Resumen: El artículo busca relacionar la geografía y la filosofía kantianas. Para Kant, la geografía sería la única ciencia capaz de trabajar el empírico y el transcendental, compondo una relación multiescalar, de acuerdo com la cual la descripción geográfica, asociada al concepto de historia de la natureza podría reconstruir los procesos e paisages del pasado y fornecer explicaciones para los paisages actuales. Otro facto importante es que la reflexión geográfica de Kant estubo fortemente embebida de una dura geografía política, que justificava epistemologicamente la ocupación de todos los espacios de la Tierra por el modo de producción capitalista, segregando los continentes y sus pueblos.

Palabras-clave: Kant. geografía física. descripción de la naturaleza. historia de la naturaleza. cosmopolitismo.

\begin{abstract}
This paper seeks to relate Kantian geography and philosophy. In one hand, for Kant geography is the only science that enables empirical and transcendental work due to the multiscale relationship according to the geographical description and to the history of nature that reconstructs the processes and landscapes of the past and also provides explanations for the landscapes today. In the other hand, an important feature on the Kantian geographical reflection was heavily steeped in a harsh political geography which epistemologically has justified the occupation of all areas of the Earth's surface by the capitalist mode of production and separated continents and their peoples.
\end{abstract}

Keywords: Kant. Physical Geography. description of nature. history of nature. cosmopolitanism. 


\section{INTRODUÇÃO}

Infelizmente na historiografia da Geografia dá-se pouca atenção ao papel da Physische Geographie kantiana, sejam os estudos do próprio Curso de Geografia Física que Kant lecionou por praticamente 40 anos na universidade de Königsberg (1756-1800), ou mesmo as discussões geográficas que permeiam e fundamentam sua filosofia crítica. Quando muito, nas disciplinas de História do Pensamento Geográfico, é reservado um breve intervalo de tempo para falar que em Kant o espaço é um a priori, como se este espaço da Crítica da Razão Pura (KANT, 1982) fosse sinônimo de geografia. O que se observa, com raras exceções, é a busca de uma correlação entre o sentido de geografia na filosofia kantiana, a sua geografia no contexto das transformações científicas da época, e a importância da Geografia na reflexão filosófica de Kant, particularmente a partir da publicação da Crítica da Faculdade do Juízo (KANT, 1995).

A nossa premissa é de que a Physische Geographie resulta de sérios problemas colocados pelo sentido de causalidade, em que estão envolvidos temas como a matéria, a contingência, o particular e a representação. Ou seja, mais importante do que a cosmografia e o mapa, a reflexão geográfica faz Kant refletir sobre o problema da experiência do sujeito, levando-o a repensar o seu esquematismo da razão, a fim de superar a problemática particular-universal, empírico-transcendental. Somente a Geografia lhe forneceu elementos para uma revolução copernicana de fato, com a epigênese da razão. As fronteiras entre filosofia e geografia em Kant são muito tênues, tanto que podemos fazer uma leitura da geograficidade da filosofia kantiana, mas também do papel da Geografia na constituição da Filosofia Crítica.

Toda esta situação se coloca, primeiramente, pelo próprio contexto de expansão da visão eurocêntrica de mundo e natureza acerca dos continentes. Também, não podemos nos esquecer de que o século XVIII e o início do XIX são marcados pelo surgimento das Ciências da Terra, com forte desenvolvimento da geologia, da paleontologia, da mineralogia, por exemplo, que irão necessitar de uma ciência que organize um corpus explicativo sobre esta nova Terra e este novo Mundo que está em construção.

\section{NATUREZA E REPRESENTAÇÃO.}

Na primeira seção da Faculdade do Juízo (KANT, 1995) denominada de 'Analítica do Belo', Kant nos fala que a beleza da natureza ou de um objeto da natureza está ligada à faculdade da imaginação do sujeito, sendo capaz de produzir prazer no sujeito (KANT, 1995); e que a faculdade de representação, quando deixada ao livre jogo da imaginação, não é capaz de produzir conhecimento. Isso, porém, só acontece quando entra em jogo o empírico. Portanto, o juízo teleológico e estético, associado à representação e a imaginação relacionando-se com o empírico, sob o jugo das leis transcendentais, é capaz de produzir conhecimento. Para que isso aconteça, participam a intuição e a sensibilidade do sujeito 
que demonstra interesse pelo objeto ou pelo conjunto de objetos em conexão, que formam uma totalidade. A natureza é uma totalidade, que, para Kant, seria o organismo.

Esta proposta kantiana de que a natureza pode ser trabalhada tanto no seu aspecto mecânico quanto no subjetivo ou de ambas as maneiras, abre um precedente metodológico heurístico, não mais metafísico sobre a natureza e as ciências que a estudam. A nosso ver, este princípio heurístico está materializado na noção de princípios regulativos teleológicos e estéticos. A teleologia constituiu-se em Kant (1995) na possibilidade de se estudar o organismo como um todo, permitindo conhecer sua organização, o que pode produzir um conhecimento relativo ao organismo no que diz respeito ao ponto de vista humano e ao seu poder de julgamento (QUARFOOD, 2006). Os produtos da natureza podem agora ser estudados empiricamente, fundamentados em uma metafísica da causalidade, que rompe a noção linear de causa e efeito assim como o organismo pode ser trabalhado sob o ponto de vista mecânico e transcendental. Agora, os organismos e espécies podem ser empiricamente organizados a partir de suas propriedades e racionalmente arranjados em um conjunto, onde a razão e a representação trabalham para a construção do conhecimento do mundo.

O organismo é uma unidade, uma totalidade que não é formada pela simples soma das partes, mas a representação e a imaginação, associadas ao entendimento, produzem o conceito de nexus effetivus, que garante um forte grau de coerência e unidade do organismo, enquanto produto de uma interação harmônica e de interação sistemática de um todo empírico (QUARFOOD, 2006). Para Kant (1995), a maior ou menor compreensão sobre o organismo e sua história depende da capacidade cognitiva do sujeito, assim como de seu conhecimento sobre a temática. Portanto, as causas são interconectadas, formando um sistema e, por analogia, pode o organismo ser compreendido como sendo o mundo, uma unidade teleológica, estética e sistemática.

O mundo para Kant é um microcosmos guiado por leis empíricas e transcendentais. Sob o ponto de vista científico, ele pode ser observado, experienciado, matematizado, como pode ser instrumentalizado e classificado em diferentes ordens de grandeza e qualidades e até em termos funcionais. Pode também ser pensado sob o ponto de vista teorético e prático. Esta proposta heurística, que a nosso ver começou a ser gestada nos Princípios Metafísicos das Ciências da Natureza (KANT, 1990), publicados em 1786, vai até Opus Postumum (KANT, 1995), sendo pouco desenvolvida por Kant. Opus Postumum, terminado por volta de 1803, indica-nos que Kant percebeu a impossibilidade de se trabalhar a Ciência e sua metodologia apenas com a metafísica e que seria necessário desenvolver uma epistemologia científica, para entender as diversas manifestações da natureza e da humanidade (GUYER, 1997; KLEINGELD, 2008; MAKKREEL, 2008; LIVINGSTONE; HARRISON, 1981).

Talvez por isto, Hartshorne $(1958,1969,1978)$ tenha se preocupado com a questão metodológica da Geografia, procurando resgatar o debate iniciado por Kant, passando por Humboldt e Hettner; pois, segundo o autor, “[...] os trabalhos metodológicos [visam] a elucidação de problemas de preocupação mútua" (HARTSHORNE, 1969, p.8). No mesmo trabalho, Hartshorne (1969, p.40), resgatando Richthofen, pondera que: 
[...] a Geografia não poderia pretender um lugar específico no mundo das ciências em termos de qualquer categoria particular de fenômenos, mas em função de seu ponto de vista e do seu método [...] o objeto específico da Geografia é estudar como a multiplicidade de fenômenos, na superfície da Terra, constitui uma unidade.

Segundo Hartshorne (1969) o interesse de Kant pela Geografia é que a esta se preocupava pela Terra enquanto morada do homem, a superfície da Terra seria o teatro de nossas experiências. O que teria sido reafirmado por Humboldt e Ritter, que criou o termo Erdkunde e Geoesfera, este último como sinônimo de superfície da Terra estudada pela Geografia. Conceito que para Hettner poderia ser tratado como envoltório da Terra (HARTSHORNE, 1969), constituído por certa espessura, onde haveria uma forte conexão e interação entre os elementos sólido, líquido, gasoso, biológico e onde atuaria a sociedade humana. Ainda para Hartshorne (1969), podemos chamar esta representação, o envoltório, de 'mundo', que era assim designado por Kant.

\section{A GEOGRAFIA FÍSICA}

Inicialmente deve-se observar que no século XVIII o conceito de ciência era extremamente amplo, muito mais do que o próprio conceito de filosofia. Além do que, é neste século que é apresentada à Europa a imensa variedade e diversidade da natureza nos mais variados continentes. Esta seria uma das razões que explicariam a diversidade de temas científicos tratados por Kant como, por exemplo, a teoria dos ventos, a esfericidade e a rotação da Terra e os terremotos, dentre outros temas (ZEHBE, 1985).

A primeira edição do Curso de Geografia Física apareceu em 1802, publicada por Friedrich Theodore Rink, que reuniu anotações de aula de vários alunos e cuja forma final foi revista e comentada por Kant (RIBAS, 2011). Estudos mais detalhados sobre este curso de geografia de Kant foram poucos, onde podemos destacar os trabalhos de Klaminski (1905), Adickes (1925) e, mais recentemente, de Ribas (2011).

Nas universidades alemãs no século XVIII, os cursos eram ministrados de maneira modular e de 1755 a 1770 Kant preparou sua tese de Magister na universidade de Königsberg para exercer a função de Privatdozent, ensinando os chamados 'tópicos científicos', pois a sua remuneração estava essencialmente ligada a aulas particulares. Assim, estes Privatdozents optavam por tópicos que eram novos e atrativos para com isto conseguir o maior número possível de alunos (ADICKES, 1925). É neste contexto que a geografia física e a antropologia apareceram inicialmente para o jovem Kant: como meios de sobrevivência. Conjuntamente a estas aulas, Kant escreve artigos científicos como estratégia para concorrer futuramente a uma vaga de professor na universidade de Königsberg. Assim, em 1754, produz um artigo acerca da rotação da Terra.

O século XVIII é marcado pela criação das academias de ciências, como a Royal Society de Londres, a Académie des Sciences de Paris e a Königliche Akademie der Wissenschaften de Berlim; além da Encyclopédie francesa, do desenvolvimento da química em laboratórios, 
com a produção do vidro, por exemplo, que demandavam a criação de uma visão sistemática sobre a natureza.

Esta mudança acontecerá em 1735 com a publicação da obra Systema Naturae por Linneu, a primeira reflexão a introduzir um sistema de classificação na ciência, ordenando e hierarquizando os diferentes elementos da natureza. Esta obra produziu um forte impacto no século XVIII e exerceu forte influência nas reflexões sobre geografia por parte de Kant. A partir desta transformação paradigmática da obra de Linneu, a ciência do século XVIII podia agora ordenar os fenômenos e classificá-los, formando assim uma estrutura interpretativa dos fatos.

Outro dado a ser realçado diz respeito ao contexto político e religioso que predominava nos principados alemães. Foi somente durante o reinado de Frederico II (o monarca esclarecido) que houve um afrouxamento na censura, o que intensificou a produção científica e filosófica de então, inclusive de manuais, como o Curso de Geografia Física de Kant, que pôde, então, produzi-los e publicá-los, como guia de suas aulas. Além deste manual, em 1755, Kant escreveu Histoire générale de la nature et theorie du ciel (KANT,1984) no qual procurou distinguir sua concepção de formação do universo, onde a palavra deus foi substituída por 'grande janela'.

Além disso, é no século XVIII que a mineralogia estava se desenvolvendo com grande intensidade e o resultado disso é a revisão sobre a história da Terra (RUDWICK, 2005), que envolvia a classificação dos minerais e a paleontologia. O mote deste momento era a coleta em campo e a formação de coleções de fósseis e minerais, que depois deveriam ser estudados e a partir daí, associado às informações de campo, eram produzidas classificações, levando à reflexão sobre a história da Terra e a evolução biológica.

A mineralogia imprimiu uma metodologia sistemática nos estudos da natureza inorgânica e serviu de base para os estudos de botânica e zoologia (RUDWICK, 2005). A mineralogia forneceu também a primeira interpretação sobre a estrutura da Terra, bem como foi utilizada para a interpretação das diferentes paisagens. Estas transformações no sentido de descoberta de uma história da Terra conduziam a gênese da geologia moderna, chamada na época de Geognosia, cujo objetivo era estudar a estrutura da Terra, produzindo uma primeira aproximação de uma visão tridimensional do espaço. À geografia física caberia a descrição deste espaço e de suas paisagens, procurando demonstrar a variabilidade espacial da natureza e as relações espaciais entre as paisagens.

É neste contexto que Kant irá produzir trabalhos sobre a idade relativa da Terra fazendo uso de informações sobre a lava produzida pelos vulcões. Diz Kant,

The lava that flows out of Mount Etna contains the same mass as four mountains like Mount Vesuvius. At night it glows like fire and when it cools, it attains the hardness of stone, so that churches can be built of it. But when new lava encounters such a church, the latter melts away. [...] Soil does not settle readily on the lava, even though the area beneath mountains where ash is present is very fertile and covered in trees the diameter of which is eighty inches.

But how did the soil come to be on the older lava? The soil gradually generated itself, for this happens even on the smoothest stone. The air first carries up dust, and then 
more similar particles accumulate there, until it turns into a real layer of soil, but this must take a very long time (KANT, 1911, v. 9, p.266).

Esta passagem demonstra como Kant procura trabalhar alguns exemplos de evidências empíricas produzidas por outros pesquisadores, mas buscando sempre construir uma associação entre os fatos, para com isto relacionar e deduzir fenômenos naturais. Da mesma forma procede quando comenta sobre a variabilidade climática, as inundações e posição das ilhas, diz Kant:

Scheuchzer and many other physicists attribute these indications of ancient change to the flood; but firstly, this covered the Earth for too short a time for it to have been able to cause these changes. A short time, such as Noah`s Flood lasted, is not sufficient to have piled up overly large banks of shells, deep layers of soil, or indeed even large rocks [....]. The flood seems to have been merely a universal example of one of these changes, that is, a change in the whole of the dry land into sea and of this back into dry land.

There are undeniable indications that this really happened in some regions of the earth, either before or after, and that many years have elapsed during such changes. The fact that many, indeed all, islands must once have been connected with the dry land, and that the land in between them was changed into sea bed, is evident from the animals that may be found on them (KANT, 1911, v. 9, p.300-1).

Inicialmente, Kant utilizou-se da obra Geografia Geral de Varenius para fundamentar o seu Curso de Geografia Física. Mas a partir de 1756 e principalmente no final do século XVIII, Kant passa a repensar a geografia como apenas uma ciência descritiva, empírica, levando-a a galgar o status de uma ciência que trabalha com a conexão entre o empírico e o transcendental. Essa mudança de perspectiva deve levar em conta a ampliação do conhecimento da Terra. Destacam-se nesse processo as viagens de circunavegação do capitão Cook, sobretudo a segunda circunavegação, realizada em 1772, da qual participaram como geógrafos de bordo Johann Reinhold Forster e Georg Forster, este último com 18 anos de idade.

O jovem Forster, focando suas observações de maneira sistemática, notabilizou-se pelas análises antropológicas (FORSTER, 2000), além de aperfeiçoar o método da observação e da descrição utilizando-se de instrumentos de mensuração que na época estavam sendo produzidos pela indústria, como fruto da revolução newtoniana.

Além destas influências, muitas vezes exercidas por intermédio de debates acalorados, como os travados por Kant e Forster ou entre Kant e Herder, outras reflexões impulsionaram Kant a intensificar a sua visão de arqueologia da natureza e da geografia física como ciência hibrida, pois, para ele, esta trabalhava com o estatuto do empírico e do transcendental para a explicação de um lugar ou de uma paisagem.

Uma destas influências foi o estudo geográfico produzido por Nicolas Desmarest, contemporâneo de Kant que, em 1757, escreveu sobre geografia física para a Encyclopédie de Diderot. Posteriormente, em 1771, realizou trabalhos de campo na província vulcânica de Auvergne, concluindo sobre a sucessão das épocas de vulcanismo e a formação dos 
vales fluviais (MAY, 1970), além de procurar estabelecer relações entre a história da ocupação daquela região com a paisagem da época. Outro naturalista-geógrafo importante é Horace Benedict de Saussure que, trabalhando nos Alpes foi o primeiro a escalar o Mont Blanc em 1787, carregando consigo vários instrumentos, como barômetros, termômetros, higrômetros, além de equipamentos geológicos. Saussure realizou observações sobre a geologia e procurou correlacionar os dados adquiridos com os instrumentos às características geomorfológicas, vegetais e de ocupação da região. Com estes dados, mais o levantamento geográfico, realizou especulações filosóficas sobe a origem da paisagem daquele período (VITTE, 2011).

Estas influências advindas do contexto científico da época, associadas às transformações em sua filosofia, particularmente as transformações no conceito de matéria e espaço, levarão Kant a propor que a geografia física defina a história da natureza como narrativa e, no extremo, como uma geografia contínua, ou seja, uma geografia advinda de seu próprio método de pesquisa, isto é, a geografia permitiria deduzir das descrições da natureza as origens mais remotas de um fenômeno na crosta terrestre.

Assim haveria um conteúdo da história e da geografia da natureza, onde a geografia é o substrato (KANT, 1923). Substrato porque o movimento incessante da história, o tempo empírico, deve reportar, deve pôr as suas marcas no espaço. Neste sentido o espaço empírico deve de um ponto de vista lógico, preceder ao tempo empírico, ou seja, o espaço empírico já deve existir para que o tempo possa iniciar o seu processo e colocar suas marcas. Neste momento de sua Physische Geographie, Kant se pergunta: O que existiu antes, História ou Geografia? É a Geografia, "pois os eventos devem relacionar-se a partir de algo" (KANT, 1923, p.163). A História, nesse momento lógico, é tomada no sentido de um tempo incessante e algo vazio, não ainda a história da natureza, mas o tempo. Esse tempo separado do espaço, da Geografia, não muda, ele é apenas um progresso contínuo (KANT, 1923). E são as transformações das coisas, 'as coisas se transformam' (die Dinge verändern sich), remetidas a 'tempos certos' (gewissen Zeiten), que originam as geografias parciais e a narrativa de todas elas constitui a completa história da natureza.

Na Physische Geographie também aparece uma distinção entre Geschichte e Historie. Para Kant, a Geschichte deve ser uma narrativa (Erzählung, Historie) e não uma descrição (Deschreigung), que deve ser tomada preventivamente como uma 'descrição geográfica da natureza' (geographische Naturbeschreibung). Para Kant, Geografia e História preenchem a totalidade do campo dos nossos conhecimentos; do espaço na Geografia, e do tempo na História (KANT, 1923).

Correlacionando as questões filosóficas com a natureza da Geografia, Kant deixa claro ao longo de suas reflexões que o lugar e o espaço constituem-se em uma importante estrutura em seu pensamento filosófico geográfico. A noção de organismo e sua transformação em Kant ocorrem devido às particularidades da natureza, diríamos devido às interações do lugar com os sistemas orgânicos, levando com isto às transformações das espécies, que futuramente serão trabalhadas por Darwin.

Então, a nosso ver, o lugar joga um importante papel na reconstituição da Filosofiageografia kantiana, obrigando Kant a repensar a sua concepção de razão já que o lugar 
gera particularidades e inclusive interfere na dinâmica da especiação e em último caso na diferenciação das paisagens. No caso da Geografia, à medida que a epigênese da razão é requalificada, rompendo com o mecanicismo de cunho newtoniano, o espaço, agora enquanto espaço geográfico é proposto por Kant como um organismo que se materializa em sistemas orgânicos. Reformulando essa proposição em uma linguagem contemporânea, poderíamos falar, por exemplo, em zonas ou mesmo em domínios morfoclimáticos, que a partir da noção de causalidade da causa, aquilo que chamamos de metafísica da causalidade, interfere na geração de eventos-eventos, na transmissão de matéria e energia no sistema natural e na constituição de morfotipos que estariam em equilíbrio com o organismo em sua totalidade e em interação constante entre o particular e o universal.

Então temos aqui uma situação que nos leva a pergunta inicial deste artigo e a situação é a seguinte: a Geografia (lugar, espaço) colocou um problema para a Filosofia Crítica, que aparece muito bem na Physische Geographie e que fundamentou a busca filosófica de Kant, a de estabelecer as conexões entre o lugar, os limites e o organismo. Situação fundamental na filosofia kantiana, pois se a crítica do julgamento teleológico coloca como premissa o organismo como se autodesenvolvendo e ao mesmo tempo se autolimitando, o salto qualitativo da epigênese da razão acontece apenas com a resolução do problema do lugar-espaço (CASEY, 1997). Este problema será parcialmente tratado em Kant, que atribuirá uma liberdade relativa para a imaginação, e aprofundado futuramente pelo 'Círculo de Jena', sobretudo por Alexander Von Humboldt.

Então, mais do que ler apressadamente a Physische Geographie e confundir o sentido e o papel filosófico da descrição em Kant, devemos relembrar que a Geografia trabalha não só com a arqueologia da natureza, mas também com o tempo presente desta natureza, que se materializa em zonas morfoclimáticas, cada qual com sua especificidade e particularidade (ABREU, 1982). Então há aqui um problema de ordem filosófica colocada pela Geografia para Kant e envolve a noção de limites da razão. Daí o juízo teleológico retrabalhar o sentido de empírico e de descrição e a imaginação ir buscar o sentido de harmonia, para construir e explicar um modelo de natureza que é universal, mas ao mesmo tempo diversa e diferencial. Então, o julgamento, que reconstrói a noção de razão em Kant ao mesmo tempo em que deve legitimar as leis mecânicas de uma natureza empírica, deve construir princípios que permitam compreender o fenômeno orgânico como uma totalidade.

Na obra Pedagogia (KANT, 2003), Kant afirma que o problema dos mapas é o mesmo da filosofia, ou seja, estabelecer os limites e explicá-los de maneira racional. E os limites do mapa e do organismo impõem limites para a razão, daí Kant, fortemente influenciado por Rousseau, dizer que a criança e o pesquisador devem cada qual a seu modo, usar a imaginação para estabelecer as correlações e inter-relações entre os lugares, os organismos visíveis - com a licença do leitor, poderíamos citar como exemplo o limite entre uma floresta tropical úmida e uma semicaducifólia, ou mesmo limites entre processos geomorfológicos em uma vertente muito urbanizada. Para Kant (1992), o estabelecimento destes limites se faz com o uso da imaginação, guiada pela razão, ou seja, a partir de dados empíricos. Para ele, a razão deve buscar uma regularidade nos registros ou no experimento e, a partir daí, estabelecer limites. Para Kant ([1802] 2003) os limites geográficos são importantes, pois 
obrigam a razão a conectar sempre o lugar ao desenvolvimento do organismo e, ao mesmo tempo, a sempre repensar a ideia de regularidade e a funcionalidade do organismo.

Assim, dado o contexto histórico da época, Kant foi obrigado a repensar sua filosofia crítica, e a grande estrutura desta reflexão foi a conexão lugar-organismo, levando-o de uma reflexão metafísica para uma epistemológica nas ciências, na medida em que o conceito de organismo exigiu uma reflexão sobre a descrição da natureza (Naturbeschreibung), que por sua vez deve ser feita utilizando-se de um conceito de história natural (Naturgeschichte). Assim, somente do ponto de vista científico poderia um organismo (como a paisagem, o relevo, formação florestal, por exemplo) ser identificado e suas particularidades compreendidas. Inicialmente, os organismos poderiam ser classificados, daí a importância da Geografia que, nesse momento, seria, no linguajar de Kant, propedêutica, ou seja, faria apenas uma descrição natural, guiada pelo critério de sistematicidade da razão, chegando assim a um sistema de classificação formal. Esta classificação, que seria uma divisão natural do organismo, deveria ser compreendida dentro de uma história natural do organismo, onde suas particularidades seriam sempre relativas e remeteriam às transformações espaços-temporais do organismo e da totalidade.

Kant, em sua Physische Geographie (1802), frisa muito bem o papel das diferenças entre os lugares na geração de organismos (paisagens, espécies - exemplos nossos), que, segundo o mesmo Kant, poderia marcar certa linearidade do organismo ao longo do tempo, que seria dada por uma conexão entre o lugar e as espécies. Para ele, os lugares são o ponto matricial na história da natureza, podendo ou não levar a uma transformação do sistema natural, por isto ele, Kant, concebe da mais suma importância a descrição geográfica, pois somente ela pode fornecer à razão os pontos do espaço onde as particularidades do lugar atuam na dinâmica e na transformação dos organismos.

Em termos filosóficos Kant atribui somente à Physische Geographie a capacidade de trabalhar a conexão entre as razões intrínsecas e as extrínsecas no processo de evolução de um organismo e a sua diferenciação, o que o obrigou a repensar o sentido de razão na filosofia.

\section{O PAPEL DA DESCRIÇÃO GEOGRÁFICA PARA KANT}

Para Kant, o conhecimento geográfico produziria um conhecimento sistemático e total da Terra, de tal maneira que poderia dar ao sujeito condições para ter experiências nos mais diferentes lugares, isto porque a geografia produzia e ao mesmo tempo estava ligada a uma visão sistemática de natureza.

Kant já notara em seu Physische Geographie, que a geografia possuía particularidades quanto ao método e ao objeto, isto porque trabalha em estreita relação com a narrativa e a descrição, ou entre a explicação e a apresentação de um fenômeno na superfície da Terra. A geografia em Kant é uma disciplina unitária, mas cujo objeto é a diferenciação do espaço. Sob o ponto de vista metodológico, esta diferenciação do espaço deve ser tratada inicialmente por meio da descrição da Terra [do 'lugar, grifo nosso], para que o fenômeno 
possa ser compreendido em seu lugar geográfico. A descrição permite a construção, por meio do jogo entre razão e imaginação, do senso de espacialidade do fenômeno em um determinado lugar geográfico.

Para Kant há dois tipos de descrição. Uma trata da temporalidade do objeto, mais propriamente da sucessão dos eventos em um lugar: "History concerns the events that have taken place one after another in time. Geography concerns phenomena that occur simultaneously in space" (KANT, 1802, apud ADICKES, 1911, p.169).

A simultaneidade dos eventos determina uma ordem especial. Devemos lembrar que logo após a Crítica da Razão Pura (KANT, 1982), a concepção de espaço é revista e este deixa de ser um dado a priori da razão e passa a ser concebido como uma ordem possível de coexistência, concepção de Leibniz que será reformulada na Crítica da Faculdade do Juízo (KANT, 1995). Assim, se simultaneidade e instantaneidade são da ordem temporal na Crítica da Razão Pura cujo objetivo é dar a noção de sucessão para que a experiência se realize; na Terceira Crítica, a simultaneidade passa a ser concebida como sendo possível de existir a partir de características espaciais, pois o que está em jogo agora é o novo sentido de experiência perceptiva, que passa, então, a estar ligada ao espaço e não ao tempo. Assim, a percepção da simultaneidade é dada pela experiência da percepção das diferenças dos lugares no espaço.

Como exemplo, Kant cita as diferenças entre as raças humanas. Para ele, a humanidade descende de um único tronco, mas as diferenças entre as raças são explicadas devido à sucessão de gerações vivendo sob diferentes climas, geografias e histórias, que, segundo Kant, provocariam transformações na hereditariedade (MIKKELSEN, 2012).

A Geografia é uma ciência com a peculiaridade de trabalhar o empírico e o transcendental, com um objeto e com um método específico, diz Kant. Esta especificidade é dada na medida em que as questões geográficas podem articular a sua explicação a partir das diferenças espaciais, sendo o espaço a estrutura articuladora do empírico e do transcendental. Portanto, já em Kant, a localização espacial é fundamental para a distinção entre as espécies e a classificação dos diferentes sistemas orgânicos.

Emerge nesta discussão, seja na Physiche Geographie (KANT, 1802, 1923) ou na Pedagogia (KANT, 2003), a questão do mapa. Pois se a Geografia é uma ciência que se constitui de acordo com o espaço, o mapa é sua representação simbólica. O mapa põe em discussão os limites e as fronteiras, e Kant procura diferenciar bem entre os dois conceitos, onde o limite é o da razão e a fronteira é a da geografia. Portanto, na fronteira a razão deve buscar os limites, seja dos territórios ou dos organismos. Assim, o mapa institui a obrigação da razão se repensar, pois os limites do mapa, mais propriamente das realidades espaciais, obrigam Kant a refletir sobre os limites da razão, daí a sua epigênese da razão, que trabalhará tanto com o empírico quanto com o transcendental, em um jogo dialético em que participa a imaginação.

O mapa permite a visualização da realidade, assim como do passado e potencializa a imaginação a refletir sobre o futuro (KANT, 2008; NUSSBAUM, 1997). O mapa é do domínio da memória, diz Kant, mas não pode ser confundido com uma função espacial 
ou o próprio espaço. O mapa é apenas um instrumento que auxilia a percepção e o entendimento da ordem espacial; é, antes de tudo, uma representação espacial.

No julgamento teleológico e no estético da Crítica da Faculdade de Julgar (KANT, 1995), Kant faz a distinção entre forma e figura. A primeira esta para o espaço, a segunda para o mapa ou a pintura de paisagem, abertura que permitiu a Alexander Von Humboldt utilizar a pintura de paisagem e o próprio conceito de paisagem como representação e sinônimo de espaço geográfico.

\section{A PAZ PERPÉTUA: GEOGRAFIA POLÍTICA E COMUNIDADE EM KANT}

As leituras sobre a geografia kantiana são multifacetadas e ao mesmo tempo, devido ao fato de que não será apenas na Physische Geographie que encontraremos questões geográficas, torna-se árdua a construção arqueológica de uma geografia da razão na sua filosofia e de uma reflexão geográfica kantiana. Ainda mais na fase contemporânea com o processo de globalização, reestruturação das economias, marginalidade e segregação espacial entre países, miséria humana e forte degradação ambiental. A reflexão geográfico-filosófica de Kant e sua Physische Geographie é um apelo para repensarmos a unidade e a diferença dos lugares do sistema Terra-Mundo, reclamando o direito universal de cuidarmos da face da Terra. O juízo reflexionante teleológico e estético fundamenta o papel político da comunidade nos cuidados com o mundo (ARENDT, 2012). Isto significa que em sua teoria política Kant percebe e rechaça a forma como alguns países europeus tratavam os povos dos novos continentes, que eram incluídos no cotidiano da ocidentalização do mundo (LATOUCHE, 1996). É por isto que não poderíamos deixar de escrever algumas páginas sobre a questão da geografia política em Kant e de seu sentido de comunidade. Nesse aspecto, a obra mais importante de Kant é A Paz Perpétua (KANT, 2008), mas podemos citar também como referências valiosas para o estudo da geografia política, as obras $O$ Direito (1997) e A Metafisica dos Costumes (2005), por exemplo.

A geografia política de Kant parte do princípio de que uma sociedade civil é guiada por leis universais. E que a característica desta sociedade e da materialização do conceito de universalidade irá depender das peculiaridades geográficas, históricas e antropológicas da comunidade.

Podemos dizer que a partir da relação entre a Physische Geographie e A Teoria do Direito, Kant reflete sobre a superfície da Terra como a unidade de todos os lugares e emprega uma combinação entre a noção de comunidade original e os fundamentos da lei.

A partir da premissa de que a Terra é a união de todos os lugares, Kant procura conectar esta premissa com a de possessão comunitária do lugar, que para ele seriam comunidades que viveriam em estado de natureza. Para isto, faz uma distinção entre possessão universal e possessão coletivamente universal. A primeira diz respeito a uma relação espacial entre uma comunidade e a posse do lugar. A segunda é a relação de posse comunal recíproca de todas as comunidades sobre a Terra, vista como um bem comum. Isto seria atingido com o esclarecimento e a vivência cosmopolita das comunidades, cada 
qual com sua vivência de espaço e de tempo. Kant chamará o direito das comunidades de todos os lugares a viverem as suas realidades de possessão inteligível (possessio noumenon), demonstrando que as representações que as comunidades têm de si e da natureza, o entorno geográfico, denotam por si sós uma forte conexão externa e ao mesmo tempo subjetiva da comunidade com o lugar (KANT, 2005).

As leis jurídicas para Kant deveriam estar fortemente atreladas às estruturas geográficas, em que a qualidade do lugar permitiria à comunidade definir os limites da razão humana, assim como o direito de possessão da superfície da Terra.

Aí entra um forte componente da geografia política, pois Kant concebe a Terra como que já dividida entre os Estados-Nação, colocando um problema para sua teoria da comunidade e da união cosmopolita de todos os lugares, que levaria à gestão democrática da Terra e do Mundo. O problema está no fato de que os Estados impõem territorialidades às comunidades, que passam a ser geridas pelos direitos dos respectivos Estados, produzindo uma desigualdade perpétua entre comunidades e sociedades em que o Estado é o mentor do projeto cosmopolita.

Entra em cena uma pergunta: qual o papel do Estado e do Território no pensamento político de Kant?

Walter Mignolo (MIGNOLO, 2005) afirma que se em 1560, Abraham Ortelius ao publicar a sua obra cartográfica Theatrum Orbis Terrarun, na qual demonstrou a configuração das terras e oceanos do globo, sob o ponto de vista político, econômico e gnosiológico; atrelou as territorialidades ao mapa; Kant, por sua vez, no século XVIII, quando tratou sobre a questão da civilização e da cultura, inaugurou uma concepção de humanitas, que foi cartograficamente amarrada à Europa, enquanto que o resto do mundo foi chamado de primitivo, antropos.

Tal qual o atlas de Ortelius, Kant colocou a Europa no centro geométrico da história intelectual, emergindo daí a discussão epistemológica sobre a experiência, que permitia e justificava o domínio do mundo como superfície universal, advindo disto, o domínio territorial por parte dos Estados europeus sobre a superfície da Terra. Daí o theatrum mundi que, como palco do imperialismo, passa a ser epistemologicamente justificado por Kant, contra aquilo que ele mesmo chamou de "irrational epistemic exuberance" (KANT, 1923, p. 458), terras habitadas pelos Antropos (que seriam os pagãos, os infiéis, indianos, orientais, africanos, ameríndios e mulheres, por exemplo). Por sua vez, os povos da Europa, já possuidores de uma natureza humana universal, portanto cosmopolita, seriam os humanitas, aqueles que possuíam conhecimento, que eram esclarecidos.

Assim, em termos históricos e de geografia política, devemos ler de maneira interconectada a Physische Geographie e a Antropologia, pois ao descreverem os lugares e as pessoas, inserem o que Mignolo (2005) chamou de racismo epistêmico, pois ao falar do caráter nacional (KANT, 2008), Kant exclui as comunidades primitivas, que eram os povos das Américas, da África, do Oriente, por exemplo, que, para ele, não eram povos racionais. Assim, a geografia política de Kant possibilitou uma prática imperialista por parte da Europa sobre o mundo, que na concepção de Kant (KANT, 1923), o mundo era o que 
podia ser conhecido pela razão humana. Isto significa que Kant justifica o conhecimento como parte integral do processo imperial de apropriação do sistema Terra-Mundo.

Para Harvey (2009) não podemos ler Kant sob um ponto de vista determinístico, pois se é verdade que ele viveu o eurocentrismo, por outro lado, a sua geografia e a sua antropologia, interconectadas, permitiriam pensar em uma ética cosmopolita, para as comunidades, inclusive com o direito dos indivíduos de viverem em diferentes espaços, para além das fronteiras dos Estados nacionais. Para Harvey (2009), um dos múltiplos potenciais de Kant para a geografia e para se repensar o mundo é a noção de espaço relacional e de conhecimento prático do mundo, os quais permitiriam pensar a liberdade no mundo e as suas potencialidades.

\section{CONSIDERAÇÕES FINAIS}

A Physische Geographie de Kant, assim como outras obras em que a reflexão geográfica se apresenta como estruturante de um pensamento crítico, leva-nos a refletir sobre a complexidade do conceito de geografia em Kant. Esta complexidade está, a nosso ver, relacionada ao fato de que em Kant a reflexão geográfica possui forte embasamento filosófico e que somente a partir disso o filósofo chegou a pensar em uma epistemologia da ciência. É neste quadro de complexidade que devemos ler o significado que Kant atribui à expressão 'descrição da natureza'. Esta não é meramente empírica, mas dotada também de relevância universal, teórica, transcendental nos dizeres de Kant.

O importante a ressaltar também é que a descrição, associada à razão, permite reconstruir a história da natureza e as transformações do espaço. E neste, é fundamental em Kant a noção de lugar, fato que será desenvolvido em Humboldt, com a noção de região e espacialidade da natureza.

Deve-se destacar que o pensamento geográfico em Kant não se restringe apenas à Physische Geographie - aliás, se tomarmos apenas esta como referência central, pouco ou quase nada da riqueza do pensamento geográfico de Kant pode nos ser revelada. A associação desta com as demais obras revela-nos uma riqueza conceitual, em que se destaca o papel do espaço e da localização do lugar na determinação do conhecimento do mundo.

Não podemos deixar de frisar também que Kant, em seu contexto eurocêntrico, expressou uma epistemologia que justificou a incorporação e a dominação do mundo pelo modo de produção nascente. Assim, vemos como uma linha de trabalho a ser desenvolvida a questão da geografia política em Kant, já que em suas reflexões o mapa, o limite e a fronteira foram fundamentais para se pensar a relação comunidade, natureza, espaço.

\section{REFERÊNCIAS}

ABREU, Adilson Avansi de. Teoria Geomorfológica: aplicação e reflexão. São Paulo, 1982. Tese (Livre Docência em Geografia) - Universidade de São Paulo.

ADICKES, Erich. Untersuchungen zur Kants physische Geographie. Tübingen: Mohr, 1911. 
ARENDT, Hanna. Conferencia sobre la filosofia politica de Kant. Buenos Aires: Paidos, 2012.

CASEY, Eduard. The fate of place. Berkeley: University of California Press, 1997.

FORSTER, Georg. A voyage round the world. San Diego: Hawaii University Press, 2000.

GUYER, Paul. Kant and the claims of taste. Cambridge: Cambridge University Press, 1997.

HARTSHORNE, Richard. The concept of geography as a science of space, from Kant and Humboldt to Hettner. Annals of the Association of American Geographers, v. 48, n. 2, p. 97-109, 1958.

Questões sobre a natureza da Geografia. Rio de Janeiro: Instituto Pan-Americano de Geografia e História-Comissão de Geografia, 1969.

Propósitos e natureza da Geografia. 2.ed. São Paulo: HUCITEC/EDUSP, 1978.

HARVEY, David. Cosmopolitanism and the Geographies of Freedom. New York: Columbia University Press, 2009.

KANT, Immanuel. Physische Geographie. Königsberg: Theodore Rink, 1802.

. Physical Geography. Cambridge: Cambridge Editions, 1911. 9 v.

Physische Geographie. Berlim: Akademie Ausgabe of the Gesammelten Schriften, 1923.

Histoire générale de la nature et theorie du ciel. Paris: Vrin, 1984.

Princípios metafísicos da ciência da natureza. Porto: Edições 70, 1990.

Opus Postumum. Cambridge: Cambridge University Press, 1995.

O Direito. Porto: Almedina, 1997.

. Crítica da Razão Pura. Lisboa: Fundação Gulbenkian, 1982.

Crítica da Faculdade do Juízo. Rio de Janeiro: Forense Universitária, 1995.

Pedagogía. 2.ed. Madrid: Akal, 2003.

A metafísica dos costumes. Lisboa: Fundação Gulbenkian, 2005.

A antropologia de um ponto de vista pragmático. São Paulo: Iluminuras, 2008.

A paz perpétua. Rio de Janeiro: L\&PM, 2008.

KLAMINSKI, Willy. Über Immanuel Kants Schriften zur physischen Geographie. Ein Beitrag zur Methodik der Erdkunde. Königsberg, 1905. Tese (Doutorado) - Könisberg Universität.

KLEINGELD, Pauline. Kant on historiography and the use of regulative ideas. Studies in History and Philosophy of Science, v. 39, n. 4, p.523-528, dez. 2008.

LATOUCHE, Serge. A ocidentalização do mundo. São Paulo: Ática, 1996.

LIVINGSTONE, David N.; HARRISON, R.T. Immanuel Kant, subjectivism, and human geography: a preliminary investigation. Transaction Institute of Britsh Geographers, v. 6, n. 3, p.359-374, 1981.

MAKKREEL, Rudolf. Kant and the development of the human and cultural sciences. Studies in History and Philosophy of Science, v. 39, n. 4, p.546-553, dez. 2008.

MAY, James A. Kant's concept of geography. Toronto: Toronto University Press, 1970.

MIGNOLO, Walter. De-Linking: globalization, Don Quixote and the Colonies. London: Macalaster College Publications, 2005. p.19-56.

MIKKELSEN, Jon. Kant and the concept of race. Chicago: University of Chicago Press, 2012.

NUSSBAUM, Martha. Kant and stoic cosmopolitanism. Journal of Political Philosophy, v. 5, n. 10, p. 8-25, mar. 1997.

QUARFOOD, Marcel. Kant on biological theleology: towards a two-level interpretation. Studies in History and Philosophy of Science, v. 37, n. 4, p.735-747, dez. 2006. 
RIBAS, Alexandre Domingues. Cosmologia e Geografia Física em Immanuel Kant. Campinas, 2011. Tese (Doutorado em Geografia) - Universidade de Campinas.

RUDWICK, Martin. Bursting the limits of Time. Chicago: University of Chicago Press, 2005.

STARK, Werner. Das manuscript Dönhoff-eine unverhoffte Quelle zu Kants Vorlesungen über Physiche Geographie. Kant-Studien, v. 100, p. 107-109, 2009.

VITTE, Antonio Carlos. A ciência humboldtiana e a geografia física. Mercator, v. 10, n.23, set/dez., p.71-82, 2011.

ZEHBE, Jürgem. Einleitung: Die Bedeutung der Naturwissenschaften für die Philosophie Kants. In: KANT, Immanuel. Geographische un andere naturwissenschaftliche Schriften. Hamburgo: Meiner, 1985. 